\title{
Analysis of Four Phase Interleaved Boost Converter
}

\author{
Slavomír Kaščák ${ }^{1)}$, Michal Praženica ${ }^{2)}$, Miriam Jarabicová ${ }^{3)}$ and Roman Koňarik ${ }^{4)}$ \\ 1) 2) 3) 4) University of Žilina, Department of Mechatronics and Electronics, Žilina, Slovakia, \\ e-mail: ${ }^{1)}$ slavomir.kascak@fel.uniza.sk, ${ }^{2)}$ prazenica@fel.uniza.sk, ${ }^{3)}$ miriam.jarabicova@fel.uniza.sk, \\ 4) roman.konarik@fel.uniza.sk
}

\begin{abstract}
This paper deals with analysis of the four phase interleaved DC-DC converter for higher power application. The interleaved topology is widely used due to its advantage as lower input current ripple which means volume reduction of the input capacitor. The current ripple equation of an input current for the boost operation mode and the ripple current in the individual phase of the interleaved converter using uncoupled inductor are shown. The theoretical equations are supplemented by the simulation results using the Spice simulator and by measurement on the interleaved converter.
\end{abstract}

Keywords - interleaved boost converter, uncoupled inductor, simulation, measurement.

\section{INTRODUCTION}

Nowadays, the interleaved topologies are widely used in various industry sectors, ranging from small output power to several hundred kilowatts for their attractive features [1] - [6], [10], [13] - [15].

The interleaved topologies are frequently used for following applications, such as the active PFC filter for improvement of electromagnetic compatibility [7] - [9]. The next advantage is present in the VRM application in the personal computer mother board, where the output voltage is about $1 \mathrm{~V}$, but the output current is several tens of amperes [10]. The high output current can be divided into several channels of the multiphase converter without using power devices with higher current ratings leading to decreased power losses. Another advantage is high frequency operation for the input current but the switching frequency of power devices is n-times lower for the nchannel interleaved converter. For achievement of the same current ripple it is possible to use smaller inductors in comparison to classical converter but the transient response of the interleaved convertor will be faster and therefore the dynamics will be better. The upper mentioned properties and many others contribute to increasing of the power density [1], [4].

The multiphase converter has also several disadvantageous, such as more active and/or passive components and complexity of the control algorithm. Currently, the microprocessors or digital signal controllers are powerful and this disadvantage is irrelevant.

Therefore, in this paper the advantageous features of the interleaved topology will be analyzed on four phase boost DC-DC converter. The motivation for preparing this paper is utilizing of the converter as an interface between batteries or supercapacitor and a three-phase inverter for an AC motor drive system in Electric Vehicle (EV) [4], [6], [11]- [15].
This paper is divided as follows: Firstly, the theoretical analysis is investigated for different operational mode depending on the value of the duty cycle. The switching interval is accordingly divided into four intervals. In addition, the equations of the inductor current ripple and input current ripple are given in this part. Secondly, the simulation analysis will be performed to compare current ripples with the calculated value. And finally, the measured data of the input current ripple and inductor ripple will be given proportionally as a ratio of the input current ripple to the inductor current ripple. The theoretical, simulated and measured ratio will be plotted in a graph.

\section{ANALYSIS OF Four PHASE INTERLEAVED BoOST CONVERTER}

The inductor ripple currents of the four-phase interleaved boost converter depicted in Fig. 1 are analyzed in this section. Based on these currents the input current ripple is calculated as a sum of them. These characteristics are analyzed separately for the operation modes, because the applied voltages depending on ranges of the duty ratio $D \leq 1 / 4,1 / 4 \leq D \leq 1 / 2,1 / 2 \leq D \leq 3 / 4,3 / 4 \leq D \leq 1$.

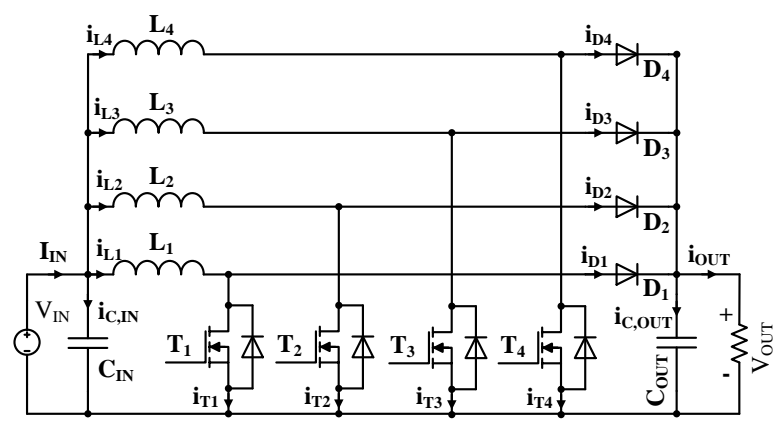

Fig. 1. Four-phase interleaved boost converter.

Figures 2, 3, 4 and 5 show the inductor current waveforms for the duty ratio less than $1 / 4$, between $1 / 4$ and $1 / 2,1 / 2$ and $3 / 4$, and greater than $3 / 4$, respectively, where $S_{1}$, $\mathrm{S}_{2}, \mathrm{~S}_{3}$ and $\mathrm{S}_{4}$ are switching signals; $i_{1}, i_{2}, i_{3}$ and $i_{4}$ are the inductor currents; $I_{1 p p}, I_{2 p p}, I_{3 p p}$, and $I_{4 p p}$ are the peak to peak amplitudes or current ripples of the $i_{1}, i_{2}, i_{3}$ and $i_{4}$ and $i_{I N}$ is the input current, which is the sum of four inductor currents and $d$ is the time interval of the increase in input current. As can be seen from the previous mentioned figures the input current ripple operates on four times frequency as compared to the inductor current. Here, the 
equations for inductor current ripples are investigated and they are given for $D \leq 1 / 4$.

$$
\begin{gathered}
I_{1 p p}=\frac{V_{\text {in }}}{L} D T_{S}, \\
I_{2 p p}=\frac{V_{\text {in }}}{L}\left(1-\frac{1}{1-D}\right) D T_{S}, \\
I_{3 p p}=\frac{V_{\text {in }}}{L}\left(1-\frac{1}{1-D}\right) D T_{S}, \\
I_{4 p p}=\frac{V_{\text {in }}}{L}\left(1-\frac{1}{1-D}\right) D T_{S}, \\
\frac{I_{I N p p}=I_{1 p p}+I_{2 p p}+I_{3 p p}+I_{4 p p}=}{V_{\text {in }}} D T_{S}\left(\frac{1-4 D}{L}\right)=\frac{V_{\text {out }}}{L} D T_{S}(1-4 D),
\end{gathered}
$$

where $V_{\text {in }}$ and $V_{\text {out }}$ are the input and output voltages of the interleaved converter, $D$ is the duty ratio and $L$ is the inductor value in Henrys. The equation (1) determines an increasing character of the inductor current $i_{1}$ and equations (2), (3) and (4) again decreasing character of the inductor currents $i_{2}, i_{3}$ and $i_{4}$.

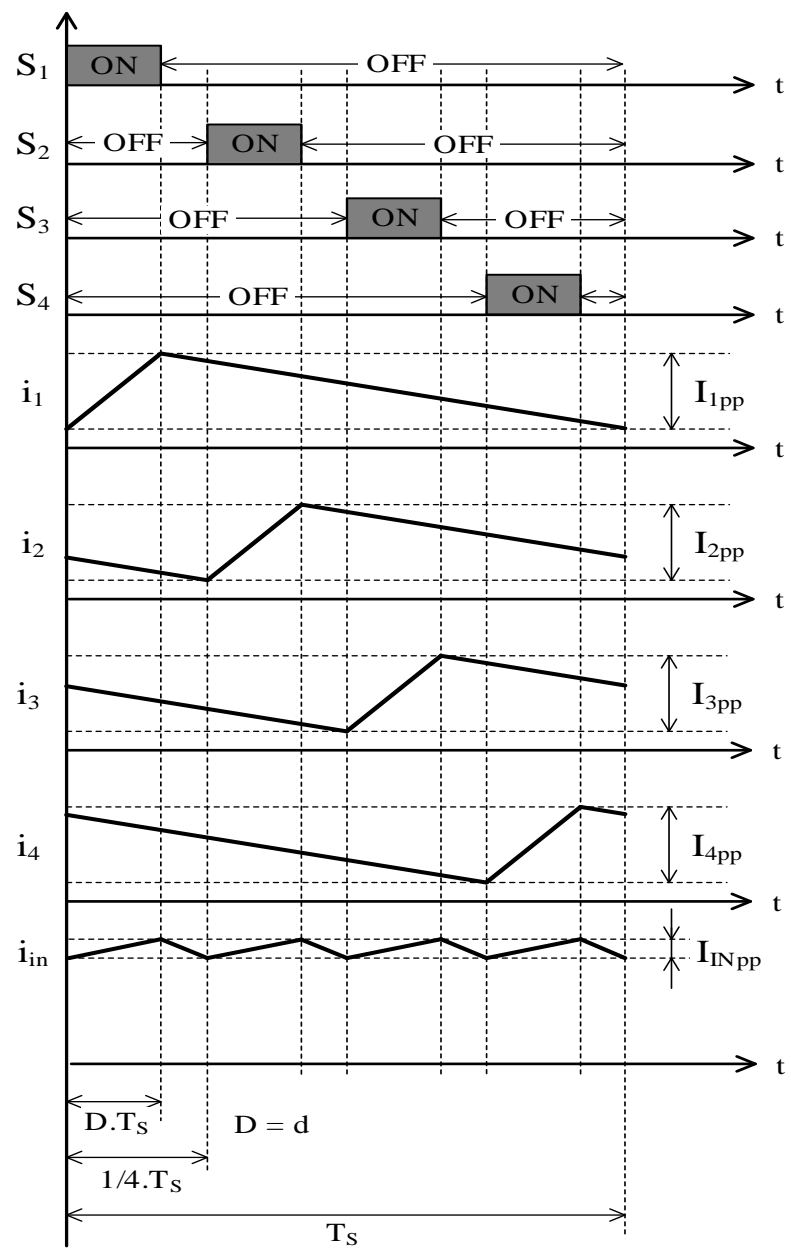

Fig. 2. Inductor current waveforms in range of the duty ratio less than $1 / 4$
Similarly, the equations for another interval of the duty ratio $1 / 4 \leq D \leq 1 / 2$ are as follows:

$$
\begin{gathered}
I_{1 p p}=\frac{V_{\text {in }}}{L} D T_{S}, \\
I_{2 p p}=\frac{V_{\text {in }}}{L}\left(1-\frac{1}{1-D}\right) D T_{S}, \\
I_{3 p p}=\frac{V_{\text {in }}}{L}\left(1-\frac{1}{1-D}\right) D T_{S}, \\
I_{4 p p}=\frac{V_{\text {in }}}{L} D T_{S}, \\
-\frac{V_{\text {in }}}{2 L} T_{S}\left(\frac{8 D^{2}-6 D+1}{1-D}\right)= \\
-\frac{V_{\text {out }}}{2 L} T_{S}\left(8 D^{2}-6 D+1\right)
\end{gathered}
$$

The value of the input current is increasing until two switches in two different phases are in on-state; in the all next states of the switches the input current has a decreasing character, as can be seen in Fig. 3 .

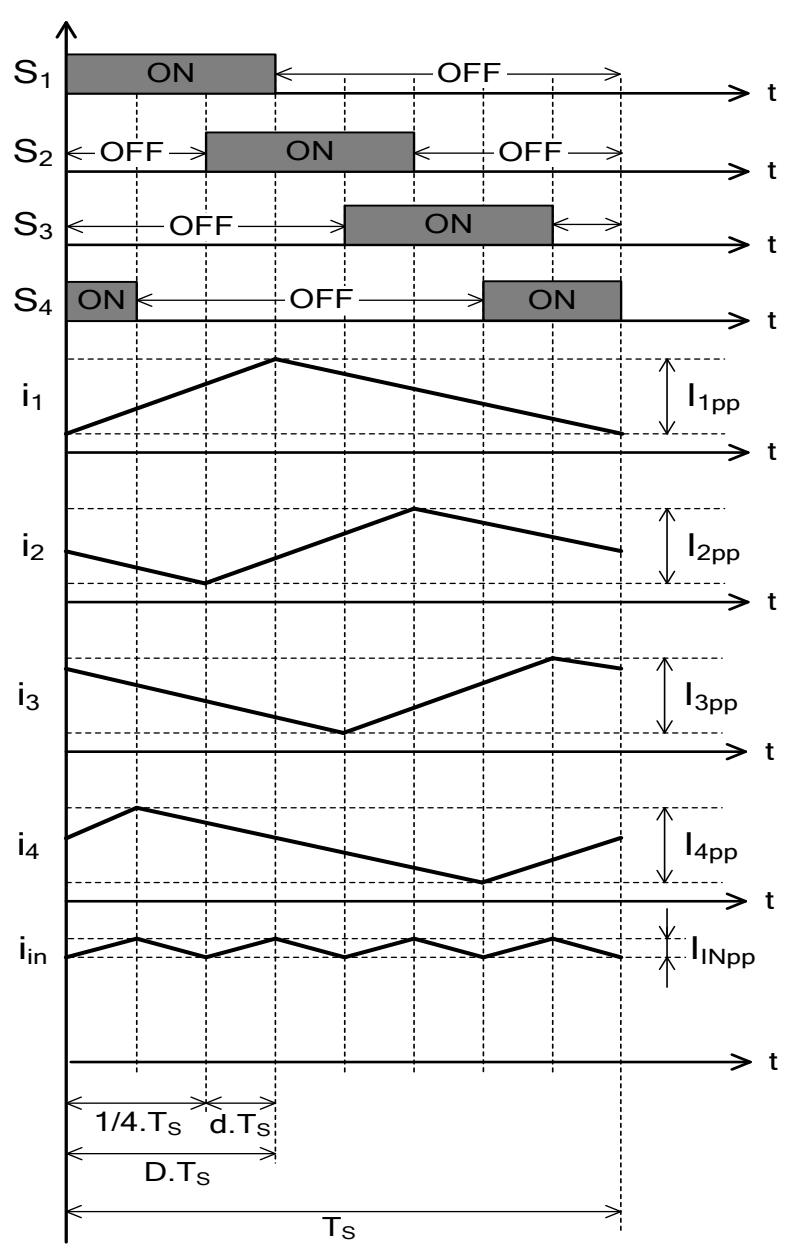

Fig. 3. Inductor current waveforms in range of the duty ratio $1 / 4 \leq D \leq 1 / 2$ 
In the third interval $1 / 2 \leq D \leq 3 / 4$, when three switches are in on-state the inductor current is increasing and therefore the input current is also increasing. When only two switches are in on-state the input current is decreasing, which is shown in the following equations and depicted in Fig. 4.

$$
\begin{gathered}
I_{1 p p}=\frac{V_{\text {in }}}{L} D T_{S}, \\
I_{2 p p}=\frac{V_{\text {in }}}{L}\left(1-\frac{1}{1-D}\right) D T_{S}, \\
I_{3 p p}=\frac{V_{\text {in }}}{L} D T_{S}, \\
I_{4 p p}=\frac{V_{\text {in }}}{L} D T_{S}, \\
-\frac{V_{\text {in }}}{2 L} T_{S}\left(\frac{8 D^{2}-10 D+3}{1-D}\right)= \\
-\frac{V_{\text {out }}}{2 L} T_{S}\left(8 D^{2}-10 D+3\right)
\end{gathered}
$$

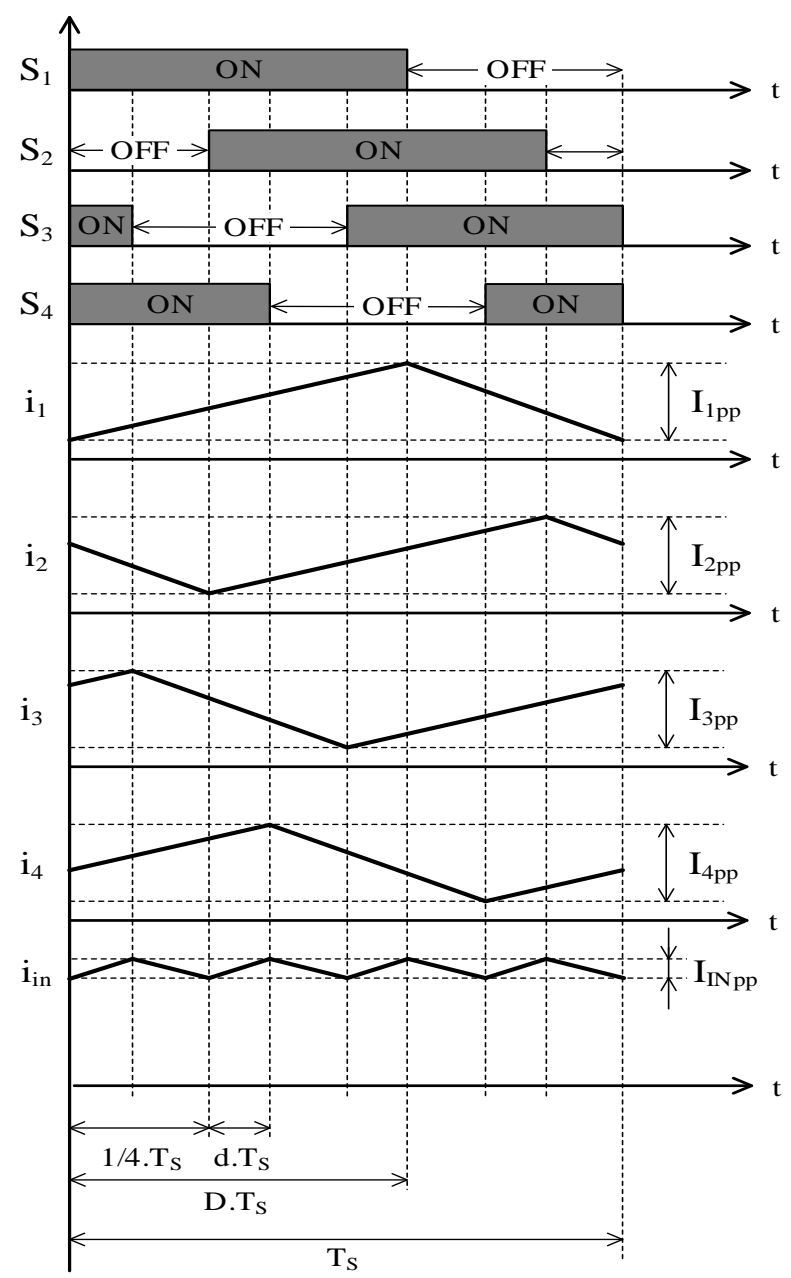

Fig. 4. Inductor current waveforms in range of the duty ratio $1 / 2 \leq D \leq 3 / 4$
In the same manner, as in the previous intervals, in the fourth interval $3 / 4 \leq D \leq 1$, when four switchers are in onstate the inductor current is increasing and if only one switch is in off-state the input current is decreasing.

$$
\begin{gathered}
I_{1 p p}=\frac{V_{i n}}{L} D T_{S}, \\
I_{2 p p}=\frac{V_{i n}}{L} D T_{S}, \\
I_{3 p p}=\frac{V_{i n}}{L} D T_{S}, \\
I_{4 p p}=\frac{V_{i n}}{L} D T_{S}, \\
I_{I N p p}=I_{1 p p}+I_{2 p p}+I_{3 p p}+I_{4 p p}= \\
\frac{V_{i n}}{L} T_{S}(3 D-2)
\end{gathered}
$$

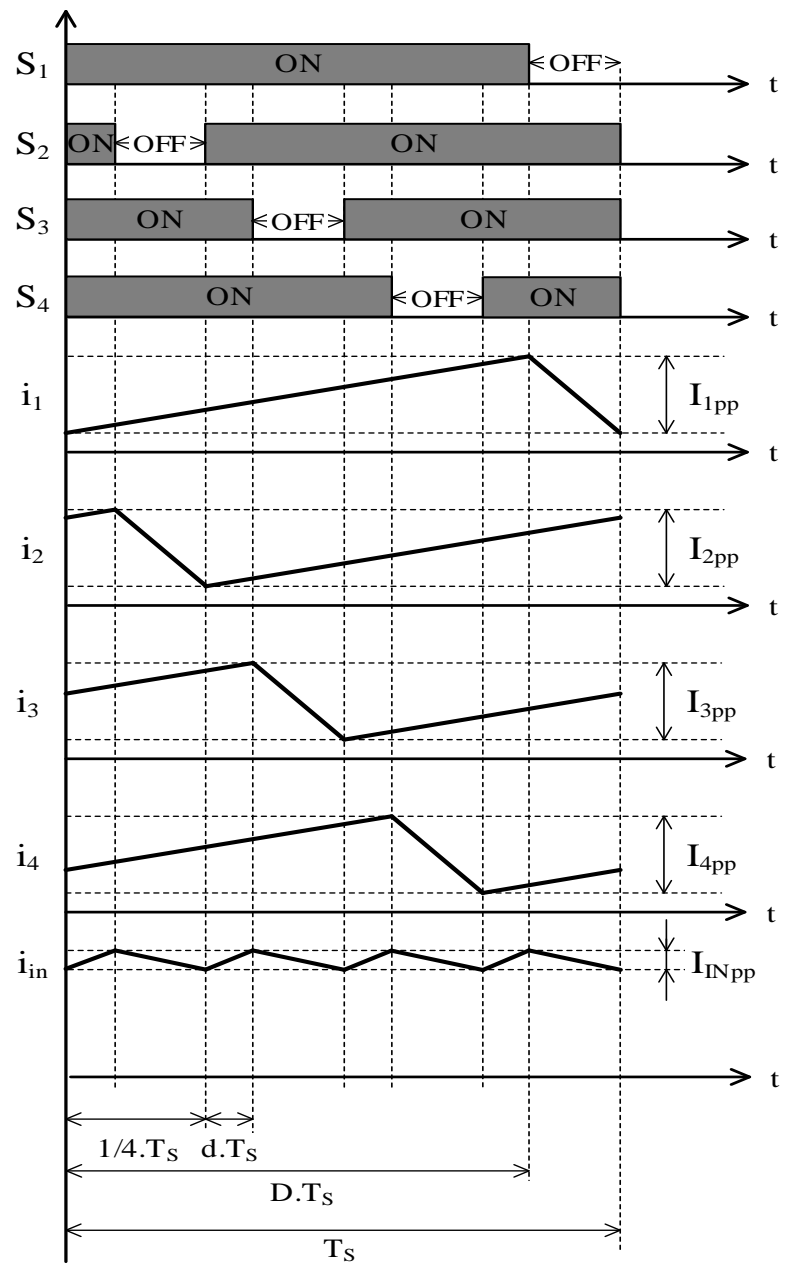

Fig. 5. Inductor current waveforms in range of the duty ratio $3 / 4 \leq D \leq 1$ 


\section{EXPERIMENTAL VERIFICATION}

Figure 6 shows the theoretical, simulated and measured ratio of the input current ripple to the inductor current ripple. From Fig. 6 it can be seen that the most preferable range of the duty ratio is approximately from 0.2 to 0.8 and even in the values of the duty ratio $D=0.25,0.5,0.75$ the ripple of the input current is almost zero and therefore the capacity of the input capacitor can be very small.

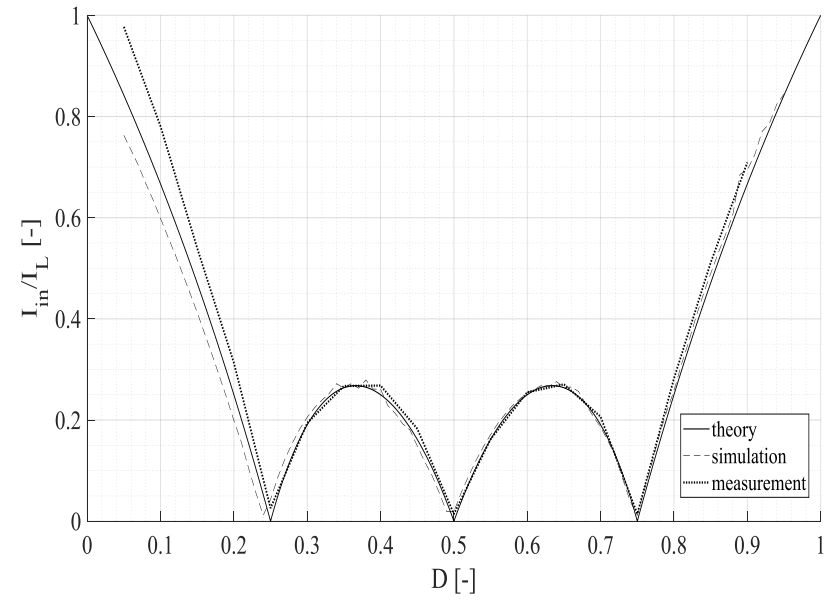

Fig. 6. The ratio of the input current ripple to the inductor current ripple.

If we imagine the axis of symmetry at the value of 0.5 , it must be mentioned that not the ripple of the inductor current or input current is equal but only the ratio of them. Because with increasing the duty ratio the dc current component is increasing what is associated with increasing of the ac current component (the ripple).

\section{CONCLUSION}

The boost converter is one of the most commonly used power converter topology covering wide range of the input and output voltages, power levels and applications. Development of the high performance and low-cost semiconductors helped commercialize multiphase topologies offering multiple benefits at only a small price premium. The four-phase interleaved boost converter operated in the continuous inductor current mode has been analysed in the steady state. Generalised expressions for the input and inductor current ripple were analysed. By investigation of the multiphase converter it was identified that a simple increasing of the phase number does not always yield to reduced component stress. The experimental results were verified in the steady-state performance of the interleaved converter. The graph of the ratio between the input current and inductor current is plotted. According the graph the value of the input capacitor can be smaller and therefore with multi-phasing the current flowing through the inductor is decreased what leads also to increasing of power density. The optimal operation of the converter is around the duty ratio of 0.25 , 0.5 , and 0.75 .

In the future work the determination of the input and output capacities, determination of the optimal number of phases and phase shedding of the unloaded phases will be presented.

\section{ACKNOWLEDGMENT}

This work was supported by projects: ITMS 26210120021, co-funded from EU sources and European Regional Development Fund, APVV-15-0571: Research of the optimum energy flow control in the electric vehicle system, VEGA 1/0928/15 - Research of electronic control of power transmission and motion of road ICE- hybrid $\mathrm{HEV}$ and EV vehicles.

\section{REFERENCES}

[1] Texas Instruments "Power Tips: When to choose multiphase" https://e2e.ti.com/blogs_/b/powerhouse/archive/2013/10/31/powerl ab-notes-when-to-choose-multiphase

[2] Bodo's Power Systems "Multiphase Buck Converters," http://www.powerguru.org/multiphase-buck-converters/

[3] R. Ovcarčík, P. Spánik, R. Pavlanin, "DC/DC converters used for a high input voltage based on a half-bridge topology," TRANSCOM 2005 : 6-th European Conference of Young Research and Science Workers in Transport and Telecommunications, Žilina, 2005, ISBN 80-8070-417-1, pp. 57-62

[4] S. Somkun, Ch. Sirisamphanwong, S. Sukchai, "A DSP-based interleaved boost DC-DC converter for fuel cell applications," International Journal of Hydrogen Energy, Volume 40, Issue 19, 25 May 2015, pp. 6391-6404, http://www.sciencedirect.com/ science/article/pii/S0360319915006680

https://doi.org/10.1016/j.ijhydene.2015.03.069

[5] N. Sundari, D. Jeba, R. Ramalakshmi, R. Rajasekaran, "A Performance Comparison of Interleaved Boost Converter and Conventional Boost Converter for Renewable Energy Application," Proceedings of 2013 International Conference on Green High Performance Computing, IEEE, 2013, pp. 6, DOI 10.1109/ICGHPC.2013.6533924, ISBN 978-1-4673-2592-9 https://doi.org/10.1109/ICGHPC.2013.6533924

[6] M. Lazić,M. Živanov, B. Šašić, ”Desing of Multiphase Boost Converter for Hybrid Fuel Cell/Battery Power Sources," Paths to Sustainable Energy, INTECH 2010, pp. 359-404, ISBN 978-953307-401-6, https://doi.org/10.5772/13113

[7] ON Semiconductor "Interleaved PFC", https://www.onsemi.com/ pub/Collateral/TND380-D.PDF

[8] M. O'Loughlin, "An Interleaving PFC Pre-Regulator for HighPower Converters," Texas Instruments, http://www.ti.com/ download/trng/docs/seminar/Topic5MO.pdf

[9] F. Musavi, W. Eberle, W. G. Dunford, "A High-Performance Single-Phase Bridgeless Interleaved PFC Converter for Plug-in Hybrid Electric Vehicle Battery Chargers," IEEE Transactions on Industry Applications, Vol. 47, No. 4, 2011 https://doi.org/10.1109/TIA.2011.2156753

[10]P.L. Wong, P. Xu, B. Yang, F.C. Lee, "Performance Improvements of Interleaving VRMs with Coupling Inductors," IEEE Transactions on Power Electronics, vol. 16, NO. 4, 2001

[11]P. Cubon, R. Radvan, "Evaluation of Propulsion System of the Electric Go-kart," In Proceedings of the 17th International Student Scientific Conference on Electrical Engineering POSTER 2013, May 16, 2013, Prague, ISBN 978-80-01-05242-6

[12]R. Mazgut, P. Cubon, R. Radvan, "Possibilities optimizing energy consumption of electric vehicle," In Proceedings of the 19th International Student Conference on Electrical Engineering POSTER 2015, ISBN 978-80-01-05728-5

[13]H. B. Shin, J. G. Park, S. K. Chung, H. W. Lee, "Generalized Steady-state Analysis of Multiphase Interleaved Boost Converter with Coupled Inductors," IEE Proceedings - Electric Power Applications, Vol. 152, No. 3, 2005 https://doi.org/10.1049/ip-epa:20045052

[14] A. Ikriannikov, "The Benefits of the Coupled Inductor Technology" Maxim Integrated, Tutorial, https://www.maximintegrated.Com /en/app-notes/index.mvp/id/5997

[15] J. Imaoka, M. Yamamoto, T. Kawashima, "High-power-density three-phase interleaved boost converter with a novel coupled inductor," IEEJ Journal of Industry Applications, Vol. 1, No. 1, pp. 20-30 